\title{
Customized Message Generation and Speech Synthesis in Response to Characteristic Behavioral Patterns of Children
}

\author{
Ho-Joon Lee and Jong C. Park \\ CS division KAIST, 335 Gwahangno (373-1 Guseong-dong), \\ Yuseong-gu, Daejeon 305-701, Republic of Korea \\ hojoon@nlp.kaist.ac.kr, park@cs.kaist.ac.kr
}

\begin{abstract}
There is a growing need for a user-friendly human-computer interaction system that can respond to various characteristics of a user in terms of behavioral patterns, mental state, and personalities. In this paper, we present a system that generates appropriate natural language spoken messages with customization for user characteristics, taking into account the fact that human behavioral patterns usually reveal one's mental state or personality subconsciously. The system is targeted at handling various situations for five-year old kindergarteners by giving them caring words during their everyday lives. With the analysis of each case study, we provide a setting for a computational method to identify user behaviroal patterns. We believe that the proposed link between the behavioral patterns and the mental state of a human user can be applied to improve not only user interactivity but also believability of the system.
\end{abstract}

Keywords: natural language processing, customized message generation, behavioral pattern recognition, speech synthesis, ubiquitous computing.

\section{Introduction}

The improvement of robot technology, along with a ubiquitous computing environment, has made it possible to utilize robots in our daily life. These robots would be especially useful as a monitoring companion for young children and the elderly who need continuous care, assisting human caretakers. Their tasks would involve protecting them from various in-door dangers and allowing them to overcome emotional instabilities by actively engaging them in the field. It is thus not surprising that there is a growing interest in a user-friendly human-computer interaction system that can respond properly to various characteristics of a user, such as behavioral pattern, mental state, and personality. For example, such a system would give appropriate warning messages to a child who keeps approaching potentially dangerous objects, and provide alarm messages to parents or a teacher when a child seems to be in an accident.

In this paper, we present a system that generates appropriate natural language spoken expressions with customization for user characteristics, taking into account the fact that human behavioral patterns usually reveal one's mental state or personality subconsciously. The system is targeted at handling various situations for five-year old 
kindergarteners by giving them caring words during their everyday lives. For this purpose, the system first identifies the behavioral patterns of children with the help of installed sensors, and then generates spoken messages with a template based approach. The remainder of this paper is organized as follows: Section 2 provides the related work on an automated caring system targeted for children, and Section 3 analyzes the kindergarten environment and sentences spoken by kindergarten teachers related to the different behavioral patterns of children. Section 4 describes the proposed behavioral pattern recognition method, and Section 5 explains our implemented system.

\section{Related Work}

Much attention has been paid recently to a ubiquitous computing environment related to the daily lives of children. UbicKids [1] introduced 3A (Kids Awareness, Kids Assistance, Kids Advice) services for helping parents taking care of their children. This work also addressed the ethical aspects of a ubiquitous kids care system, and its directions for further development.

KidsRoom [2] provided an interactive, narrative play space for children. For this purpose, it focused on the user action and interaction in the physical space, permitting collaboration with other people and objects. This system used computer vision algorithms to identify activities in the space without needing any special clothing or devices.

On the other hand, Smart Kindergarten [3] used a specific device, iBadge to detect the name and location of objects including users. Various types of sensors associated with iBadge were provided to identify children's speech, interaction, and behavior for the purpose of reporting simultaneously their everyday lives to parents and teachers.

u-SPACE [4] is a customized caring and multimedia education system for doorkey children who spend a significant amount of their time alone home. This system is designed to protect such children from physical dangers with RFID technology, and provides suitable multimedia contents to ease them with natural language processing techniques.

In this paper we will examine how various types of behavioral patterns are used for message generation and speech synthesis. To begin, we analyze the target environment in some detail.

\section{Sentence Analysis with the Behavioral Patterns}

For the customized message generation and speech synthesis system to react to the behavioral patterns of children, we collected sentences spoken by kindergarten teachers handling various types of everyday caring situations. In this section, we analyze these spoken sentences to build suitable templates for an automated message generation system corresponding to the behavioral patterns. Before getting into the analysis of the sentences, we briefly examine the targeted environment, or a kindergarten.

\subsection{Kindergarten Environment}

In a kindergarten, children spend time together sharing their space, so a kindergarten teacher usually supervises and controls a group of kindergarteners, not an individual 
kindergartener. Consequently, a child who is separated from the group can easily get into an accident such as slipping in a toilet room and toppling in the stairs, reported as the most frequent accident type in a kindergarten [5]. Therefore, we define a dangerous place as one that is not directly monitored by a teacher, such as an in-door playground when it is time to study. In addition, we regard toilet rooms, stairs, and some dangerous objects such as a hot water dispenser and a wall socket as a dangerous place too.

It is reported that 5 year old children are very easy to have an accident rather than among 0 to 6 year old children [5]. Thus we collected spoken sentences targeted for 5 year old children with various types of behavioral patterns.

\subsection{Sentence Analysis with the Repeated Behavioral Patterns}

In this section, we examine a corpus of dialogues for each such characteristic behavioral pattern, compiled from the responses to questionnaire for five kindergarten teachers. We selected nine different scenarios to simulate diverse kinds of dangerous and sensitive situations in the kindergarten targeted for four different children with distinct characteristics. Table 1 shows the profile of four children, and Table 2 shows the summary of nine scenarios.

Table 1. Profile of four different children in the scenario

\begin{tabular}{lllll}
\hline Name & Gender & Age & Personality & Characteristics \\
\hline Cheolsoo & Male & 5 & active & does not follow teachers well \\
Younghee & Female & 5 & active & follows teachers well \\
Soojin & Female & 5 & active & does not follow teachers well \\
Jieun & Female & 5 & passive & follows teachers well \\
\hline
\end{tabular}

Table 3 shows a part of responses collected from a teacher, according to the scenario as shown in Table 2. It is interesting to note that the teacher first explained the reason why a certain behavior is dangerous in some detail to a child, before just forbidding it. But as it repeated again, she then strongly forbade such a behavior, and finally, scolded the child for the repeated behavior. These three steps of reaction for the repeated behavioral patterns happened similarly to other teachers. From this observation, we adopt three types of sentence templates for message generation for repeated behavioral patterns.

Table 2. Summary of nine scenarios

\begin{tabular}{ll}
\hline$\#$ & Summary \\
\hline 1 & Younghee is playing around a wall socket. \\
2 & Cheolsoo is playing around a wall socket. \\
3 & Soojin is playing around a wall socket. \\
4 & Cheolsoo is playing around a wall socket again after receiving a warning message. \\
5 & Cheolsoo is playing around a wall socket again. \\
6 & Jieun is standing in front of a toilet room. \\
7 & Cheolsoo is standing in front of a toilet room. \\
8 & Jieun is out of the classroom when it is time to study. \\
9 & Cheolsoo is out of the classroom when it is time to study. \\
\hline
\end{tabular}


Table 3. Responses compiled from a teacher

\begin{tabular}{|c|c|}
\hline$\#$ & Response \\
\hline 1 & $\begin{array}{l}\text { 영희야! 콘센트는 전기가 흐르기 때문에 그 곳에 물건을 집어 넣으면 아주 } \\
\text { 위험해요!! } \\
\text { (Younghee! It is very dangerous putting something inside a wall socket because } \\
\text { the current is live!!!) }\end{array}$ \\
\hline 2 & $\begin{array}{l}\text { 철수야 지난번에 선생님이 콘센트에 물건 집어넣으면 위험하다고 } \\
\text { 말했지요? 그곳에서 놀지 말고 소꿉영역에서 친구들과 함께 놀아요!! } \\
\text { (Cheolsoo I said last time that it is very dangerous putting something inside a } \\
\text { wall socket! Please go to the playground to play with your friends!) }\end{array}$ \\
\hline 3 & $\begin{array}{l}\text { 수진아!! 콘센트 근처에서 장난하는 건 아주 위혐해요!! 수진이는 } \\
\text { 똑똑하니까 그곳에서 놀면 안 된다는 거 알지요? 선생님하고 약속!! } \\
\text { (Soojin!! It is very dangerous playing around a wall socket!! Because Soojin is } \\
\text { smart, I believe you understand why you should not play there! Will you promise } \\
\text { me!! }\end{array}$ \\
\hline 4 & $\begin{array}{l}\text { 철수는 선생님과 약속한 거 잊어버렸어요? 자 친구들과 다 같이 약속하자!! } \\
\text { (Cheolsoo, did you forget our promise? Let's promise it again together with all the } \\
\text { friends!!) }\end{array}$ \\
\hline 5 & $\begin{array}{l}\text { 철수야! 왜 자꾸 말을 안듣니? 선생님은 철수가 다칠까 봐 걱정이 돼서 } \\
\text { 그러는 거야!! 철수야 위험하니까 거기서 놀지 마세 요!! } \\
\text { (Cheolsoo! Why do you neglect my words again and again? I am just afraid that } \\
\text { you get injured there. Please do not play over there!!) }\end{array}$ \\
\hline
\end{tabular}

To formulate the repetition of children's behavior, we use the attention span of 5 year old children. It is generally well known that the normal attention span is 3 to 5 minutes per year of a child's age [6]. Thus we set 15 to 25 minutes as a time window for repetition, considering personality and characteristics of children.

\subsection{Sentence Analysis with the Event}

In the preceding section, we have given an analysis of sentences handling repeated behavioral patterns of children. In this section, we focus on the relation between the

Table 4. Different spoken sentences according to the event and behavior

\begin{tabular}{|c|c|c|c|c|}
\hline Event & Behavior & Spoken sent & & \\
\hline none & walking & $\begin{array}{l}\text { 철수야 } \\
\text { (Cheolsoo) }\end{array}$ & $\begin{array}{l}\text { 위험하니까 } \\
\text { (because it is } \\
\text { dangerous) }\end{array}$ & $\begin{array}{l}\text { 조심하세요. } \\
\text { (be careful) }\end{array}$ \\
\hline none & running & $\begin{array}{l}\text { 철수야 } \\
\text { (Cheolsoo) }\end{array}$ & $\begin{array}{l}\text { 화장실에서 } \\
\text { (in a toilet } \\
\text { room) }\end{array}$ & $\begin{array}{l}\text { 뛰면 안돼요. } \\
\text { (running is forbidden) }\end{array}$ \\
\hline slip & walking & $\begin{array}{l}\text { 철수야 } \\
\text { (Cheolsoo) }\end{array}$ & $\begin{array}{l}\text { 화장실에서 } \\
\text { (in a toilet } \\
\text { room) }\end{array}$ & $\begin{array}{l}\text { 뛰면 안돼요. } \\
\text { (running is forbidden) }\end{array}$ \\
\hline slip & running & $\begin{array}{l}\text { 철수야 } \\
\text { (Cheolsoo) }\end{array}$ & & $\begin{array}{l}\text { 뛰지마. } \\
\text { (do not run) }\end{array}$ \\
\hline
\end{tabular}


previous events and the current behavior. For this purpose, we constructed a speech corpus as recorded by one kindergarten teacher handling slipping or toppling events and walking or running behavioral patterns of a child. Table 4 shows the variation of the spoken sentences according to the event and behavioral patterns that happened in a toilet room.

If there was no event with a safe behavioral pattern, then the teacher just gave a normal guiding message to a child. But with a related event or dangerous behavior, the teacher gave a warning message to prevent a child from a possible danger. And if the event and dangerous behavioral patterns appeared both, the teacher delivered a strong forbidding message with an imperative sentence form. This speaking style was also observed similarly in other dangerous places such as stairs and playground slide. Taking into account these observations, we propose three types of templates for an automated message generation system. The first one delivers a guiding message; the second one a warning message; and the last one a forbidding message in an imperative form. Next, we move to the sentences with a time flow that is usually related to the schedule management of a kindergartener.

\subsection{Sentence Analysis with the Time Flow}

In a kindergarten, children are expected to behave according to the time schedule. Therefore, a day care system is able to guide a child to do proper actions during those times such as studying, eating, gargling, and playing. The following spoken sentences shown in Table 5 were also recorded by one teacher, as a part of a day time schedule.

At the beginning of a time schedule, a declarative sentence was used with a timing adverb to explain what have to be done from then on. But as the time goes by, a positive sentence was used to actively encourage expected actions. These analyses lead us to propose two types of templates for behavioral patterns with the time flow. The first one is an explanation of the current schedule and actions to do, similar to the first template as mentioned in Section 3.2. And the second one encourages actions itself with a positive sentence form which is similar to the last template in Section 3.3.

Table 5. Different spoken sentences according to the time flow

\begin{tabular}{llllll}
\hline Time & \multicolumn{3}{l}{ Spoken sentence } & & \\
\hline $13: 15$ & 철수야 & 지금은 & 양치질하러 & 갈 & 시간이에요. \\
& (Cheolsoo) & (now) & (to gargle) & (to go) & (it is time) \\
& 철수야 & & 양치질하러 & 갈 & 시간이에요. \\
& (Cheolsoo) & & (to gargle) & (to go) & (it is time) \\
& 철수야 & & 양치질하러 & & 가자 \\
& (Cheolsoo) & (to gargle) & (let's go) \\
\hline
\end{tabular}

Before the generation of a customized message for children, we first need to track the behavioral patterns. The following section illustrates how to detect such behavioral patterns of children with wearable types of sensors. 


\section{Behavioral Pattern Detection}

In the present experiment, we use six different kinds of sensors to recognize the behavioral pattern of kindergarteners. The location information recognized by an RFID tag is used both to identify a child and to trace the movement itself. Figure 1 shows pictures of the necklace style RFID tag and a sample detected result. Touch and force information indicates a dangerous behavior of a child with installed sensors around the predefined dangerous objects. The figure on the left in Figure 2 demonstrates the detection of a dangerous situation by the touch sensor. And the figure on the right indicates the frequency and intensity of the pushing event as detected by a force sensor installed on a hot water dispenser. The toppling accident and walking or running behavior can be captured by the acceleration sensor. Figure 3 shows an acceleration sensor attached to a hair band to recognize toppling events, and the shoe to detect a characteristic walking or running behavior. Walking and running behaviors can be assessed by the comparison of the magnitude of an acceleration
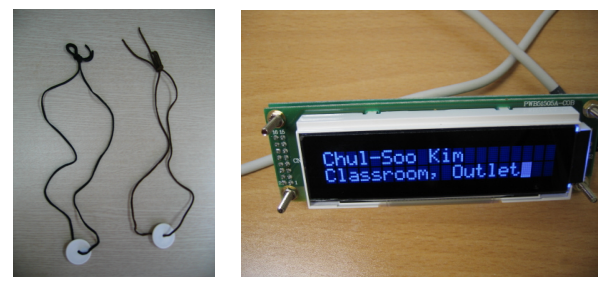

Fig. 1. Necklace style RFID tag and detected information
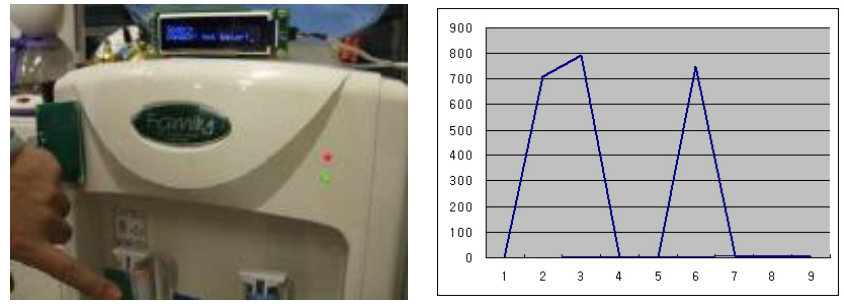

Fig. 2. Dangerous behavior detection with touch and force sensors
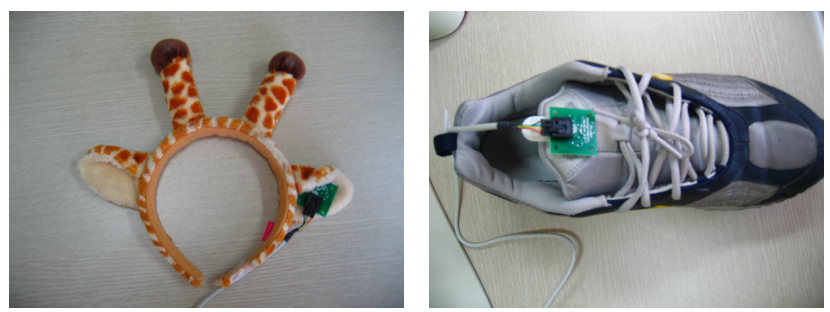

Fig. 3. Acceleration sensor attached hair band and shoe 

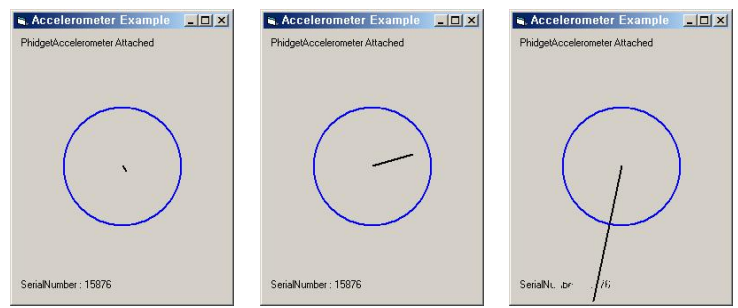

Fig. 4. Acceleration magnitude comparison to determine behavior: stop, walking, running
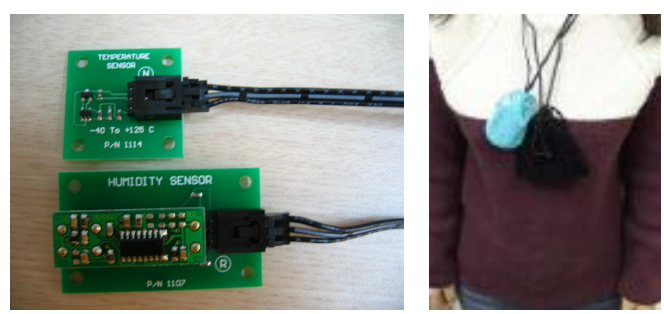

Fig. 5. Temperature and humidity sensors combined with RFID tag

value as shown in Figure 4. We also provide the temperature and humidity sensors to record the vital signs of children that can be combined with the RFID tag as shown in Figure 5.

\section{Implementation}

Figure 6 illustrates the implementation of a customized message generation system in response to behavioral patterns of children. At every second, six different sensors

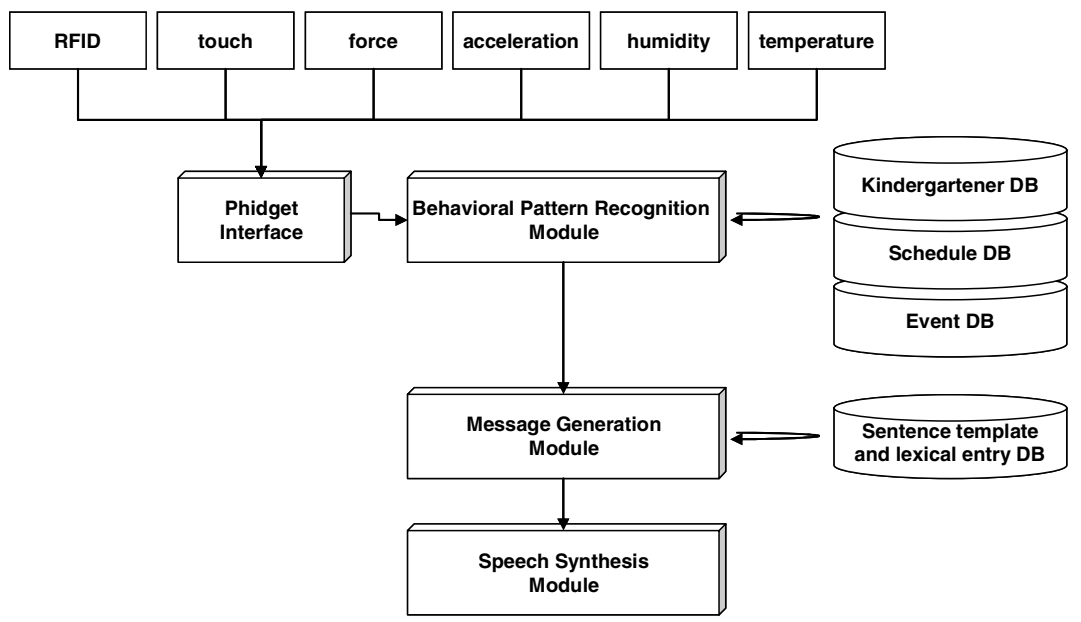

Fig. 6. System overview 

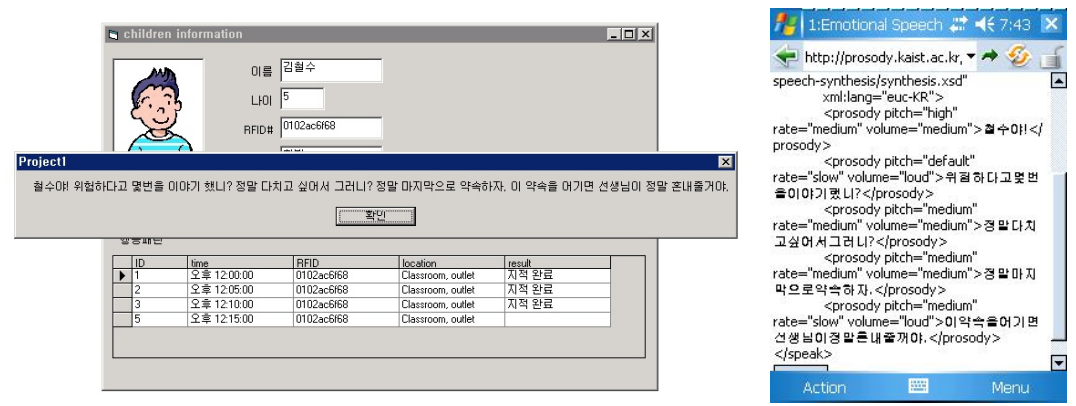

Fig. 7. Generated message and SSML document

report the detected information to the behavioral pattern recognition module through a Phidget interface which is controlled by Microsoft Visual Basic. The behavioral pattern recognition module updates this information to each database managed by Microsoft Access 2003, and delivers the proper type of a message template to the message generation module as discussed in Section 3. Then the message generation module chooses lexical entries for a given template according to the children's characteristics, and encodes the generated message into Speech Synthesis Markup Language (SSML) for a target-neutral application. This result synthesized by a Voiceware text-to-speech system in a speech synthesis module providing a web interface for mobile devices such as PDAs (the figure on the right in Figure 7) and mobile phones. Figure 7 shows the message generation result in response to the behavioral patterns of a child.

\section{Discussion}

The repetition of behavioral patterns mentioned in Section 3 is a difficult concept to formulate automatically by computer systems or even by human beings, because the usual behavioral pattern appears non-continuously in our daily lives. For example, it is very hard to say that a child who touched dangerous objects both yesterday and today has a serious repeated behavioral pattern, because we do not have any measure to formulate the relation of two separate actions. For this reason, we adopted a normal attention span for children, 15 to 25 minutes for a five-year old child, to describe the behavior patterns with a certain time window. It seems reasonable to assume that within the attention span, children perceive their previous behavior with its reactions of kindergarten teachers. As a result, we implemented our system by projecting the repetition concept to an attention span for customized message generation suitable for the identification of short-term behavioral patterns. To indicate long-term behavioral patterns, we update user characteristics as referred to in Table 1, with the enumeration of short-term behavioral patterns. For example, if a child with neutral characteristics repeats same dangerous behavior patterns ignoring strong forbidding messages within a certain attention span, we update 'neutral' characteristics as 'does not follow well'. It then affects their length of attention span interactively, such as 15 minutes for 'a child who does not follow teachers' directions well', 20 minutes for 'neutral', and 25 
minutes for 'a child who follows teachers' directions well'. By using these user characteristics, we can also make a connection between non-continuous behavioral patterns that are over the length of normal attention span. For example, if a child was described as 'does not follow well' with a series of dangerous behavioral patterns yesterday, our system can identify the same dangerous behavior happening today for the first time as a related one, and is able to generate a message to warn about the repeated behavioral pattern.

Furthermore, we addressed not only personal behavioral patterns, but relative past behaviors done by other members also, by introducing an event as mentioned in Section 3.3. This event, a kind of information sharing, increases the user interactivity and system believability by extending knowledge about the current living environment.

During the observation of each case study, we found an interesting point such that user personality hardly influences reactions on behavioral patterns, possibly because our scenarios are targeted only at guidance of kindergarteners' everyday lives. We believe that the apparent relation can be found if we expand target users to more aged people like the elderly, and if we include more emotionally inspirited situations as proposed in the u-SPACE project [4].

In this paper, we proposed a computational method to identify continuous and noncontinuous behavioral patterns. This method can be used to find some psychological syndromes such as AHDH (attention deficit hyperactivity disorder) for children as well. It can also be used to identify toppling or vital signal changes such as temperature and humidity in order provide an immediate health care report to parents or teachers, which can be directly applicable for the elderly as well. But for added convenience, a wireless environment such as iBadge [3] should be provided.

\section{Conclusion}

Generally, it is important for a human-computer interaction system to provide an attractive interface, because simply providing repeated interaction patterns for a similar situation tends to lose one's attention easily. The system must therefore be able to respond differently to the user's characteristics during interaction. In this paper, we proposed to use the behavioral patterns as an important clue for the characteristics of the corresponding user or users. For this purpose, we constructed a corpus of dialogues from five kindergarten teachers handling various types of day care situations to identify the relation between children's behavioral patterns and spoken sentences. We compiled collected dialogues into three groups and found the syntactic similarities of sentences according to the behavioral patterns of children. Also we proposed a sensor based ubiquitous kindergarten environment to detect the behavioral patterns of kindergarteners. We also implemented a customized message and speech synthesis system in response to the characteristic behavioral patterns of children. We believe that the proposed link between the behavioral patterns and the mental state of a human user can be applied to improve not only user interactivity but also believability of the system. 
Acknowledgments. This research was performed for the Intelligent Robotics Development Program, one of the 21st Century Frontier R\&D Programs, and Brain Science Research Center, funded by the Ministry of Commerce, Industry and Energy of Korea.

\section{References}

1. Ma, J., Yang, L.T., Apduhan, B.O., Huang, R., Barolli, L., Takizawa, M.: Towards a Smart World and Ubiquitous Intelligence: A Walkthrough from Smart Things to Smart Hyperspace and UbicKids. International Journal of Pervasive Computing and Communication 1, 53-68 (2005)

2. Bobick, A.F., Intille, S.S., Davis, J.W., Baird, F., Campbell, L.W., Ivanov, Y., Pinhanez, C.S., Schütte, A., Wilson, A.: The KidsRoom: A perceptually-based interactive and immersive story environment. PRESENCE: Teleoperators and Virtual Environments 8, 367-391 (1999)

3. Chen, A., Muntz, R.R., Yuen, S., Locher, I., Park, S.I., Srivastava, M.B.: A Support Infrastructures for the Smart Kindergarten. IEEE Pervasive Computing 1, 49-57 (2002)

4. Min, H.J., Park, D., Chang, E., Lee, H.J., Park, J.C.: u-SPACE: Ubiquitous Smart Parenting and Customized Education. In: Proceedings of the 15th Human Computer Interaction, vol. 1, pp. 94-102 (2006)

5. Park, S.W., Heo, Y.J., Lee, S.W., Park, J.H.: Non-Fatal Injuries among Preschool Children in Daegu and Kyungpook. Journal of Preventive Medicine and Public Health 37, 274-281 (2004)

6. Moyer, K.E., Gilmer, B.V.H.: The Concept of Attention Spans in Children. The Elementary School Journal 54, 464-466 (1954) 